\title{
Wire EleCtric Discharge MACHINING OF Metal Matrix Composite MATerials
}

\author{
SHANDILYA, P.; JAIN, P.K. \& JAIN, N.K.
}

Abstract: This chapter presents the wire electric-discharge machining (WEDM) of $\mathrm{SiC}_{\mathrm{p}} /$ Aluminum 6061 metal matrix composite $(M M C)$. Response surface methodology (RSM) has been used to plan and analyze the experiments. Four WEDM input process parameters namely servo voltage, pulse-on time, pulse-off time and wire feed rate were varied to study their effect on the quality of cut in $\mathrm{SiC}_{\mathrm{p}} / 6061$ aluminum $M M C$ using MRR and kerf as response parameters. The mathematical relationships between WEDM input process parameters and response parameters were established to determine the value of MRR and kerf mathematically. To identify the significant factors for WEDM process, analysis of variance (ANOVA) was employed. The recommended optimal process conditions have been verified by conducting confirmation experiments.

Key words: WEDM, MMC, RSM, MRR, kerf
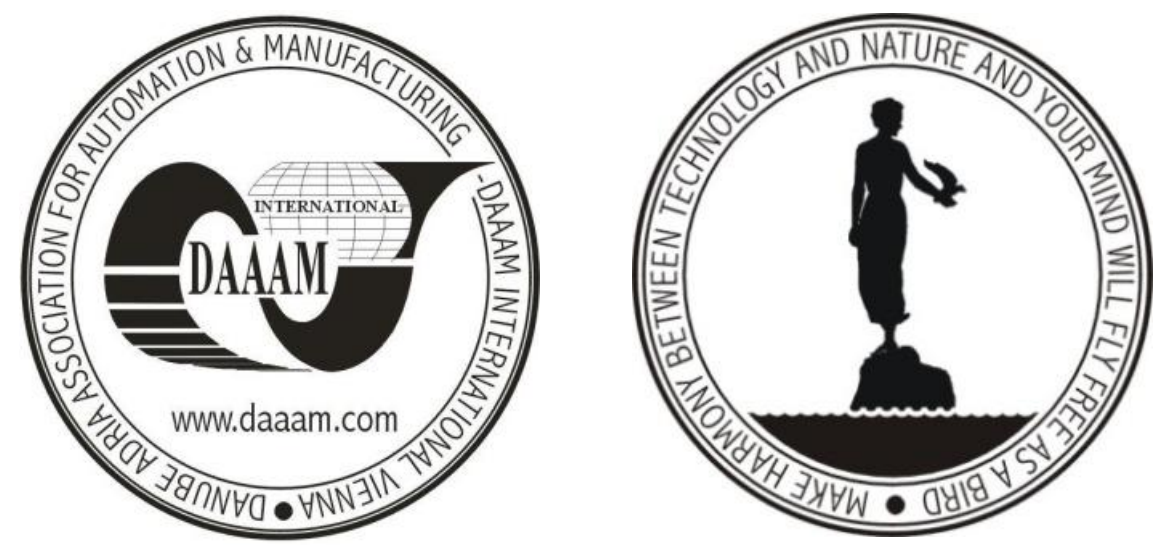

Authors' data: Shandilya, P[ragya]; Jain, P[ramod] K[umar]; Jain, N[eelesh] K[umar], Mechanical \& Industrial Engineering Department, Indian Institute of Technology Roorkee, India, pragya.shan@gmail.com

This Publication has to be referred as: Shandilya, P[ragya]; Jain, P[ramod] K[umar] \& Jain, N[eelesh] (2011). Wire Electric Discharge Machining of Metal Matrix Composite Materials, Chapter 30 in DAAAM International Scientific Book 2011, pp. 383-400, B. Katalinic (Ed.), Published by DAAAM International, ISBN 978-3-901509-84-1, ISSN 1726-9687, Vienna, Austria

DOI: $10.2507 /$ daaam.scibook.2011.30 


\section{Introduction}

With progress in science and technology, many-advanced materials have been developed. Composite material is one of them. Composite materials have conferred new dimensions to engineering. They can be designed to assure broad combinations of properties, able to fit the functional and ecological requirements of a given application, being the only way of the designed multifunctional materials producing. A composite material is a material's system composed of a mixture or combination of two or more micro or macro constituents that differ in form and chemical composition and which are essentially insoluble to each other.

Composite materials are being used increasingly in all facets of life. The everincreasing need for lightweight, strong, and inexpensive materials is driving this increased use. These materials are filling niches in the automotive industry by providing light weight, strong alternative to steels and aluminums in an effort to increase fuel efficiency. Additionally, these materials can be designed to be highly corrosion resistant, thus increasing the average life of automobiles. Composites are being used in military applications ranging from lightweight weaponry and body armor to shipboard superstructure applications. The aerospace industry use composite not only for the strength to weight properties to increased payload capacity but also for it thermal and mechanical properties in extreme environments. An example is the shielding tiles used to protect the space shuttle upon atmosphere reentry. On the basis of matrix constituent composite materials are classified as organic matrix composites (OMCs), metal matrix composites (MMCs) and ceramic matrix composites (CMCs).

One of the most widely used composite materials is metal matrix composite. Metal matrix composites are engineered materials composed of an elemental or alloy matrix in which an insoluble second phase reinforce is embedded and distributed to achieve some property improvement.

MMCs differ from other composite materials in several ways. Some of these general distinctions are as follows

1. In MMCs, the matrix phase is either a pure or alloy metal as opposes to a polymer or ceramic.

2. MMCs evidence higher ductility and toughness than ceramics or CMCs.

3. The role of the reinforcement in MMCs is to increase strength and modulus as is the case with PMCs. Reinforcement in CMCs is generally to provide improved damage tolerance.

4. MMCs have a temperature capability generally higher than polymers and PMCs less than ceramics and CMCs.

Particulate reinforced metal matrix composites constitute a major portion of these advanced materials due to its costly reinforcement particles and low costing processing techniques like casting or liquid metallurgy (Hashim et al., 1999). Aluminum-silicon metal matrix composites (MMCs) have received attention all over the world because of their attractive properties, relative ease in fabrication technology and their potential to be available at low cost (Hung et al., 1999). MMCs offer a unique balance of physical and mechanical properties. MMCs have found many successful industrial applications in recent past as high-technology materials due to their properties such as high strength-to-weight ratio, high toughness, lower value of 
coefficient of thermal expansion, good wear resistance, and capability of operating at elevated temperatures (Lindroos \& Talvitie, 1995; Rosso, 2006).

MMCs are fabricated using several processes such as casting, forging and extrusion. However, cutting and finishing operation of MMCs are not well understood. Applications of the MMCs are restricted by their poor machinability because the non conductive particles are inserted into the matrix material. So machining of the MMCs is the main issue. Machining of MMCs has been done by conventional processes as well as non-conventional processes.

Conventional machining of these materials causes serious tool wear due to the presence of abrasive reinforcing particles and thus reduced tool life (Yan \& Wang, 1993; Monaghan \& Reilly, 1992). Although, nontraditional machining techniques such as water jet machining (WJM) and laser beam machining (LBM) can be used but the machining equipment is expensive, height of the workpiece is a constraint, and surface finish obtained is not good (Muller \& Monaghan, 2000; Lau \& Lee, 1991). On the other hand, some techniques such as electric discharge machining (EDM) and wire electric discharge machining (WEDM) are quite successful for machining of MMCs. EDM has limited applications as it can be used only for drilling purpose. WEDM seems to be a better choice as it conforms to easy control and can machine intricate and complex shapes. The setting for the various process parameters required in WEDM process play crucial role in achieving optimal performance. According to Patil \& Brahmankar, 2010 during WEDM an accurate and efficient machining operation without compromising machining performance is achievable. Effective and economical WEDM of MMCs will open new areas of applications for MMCs. The most important performance measures in WEDM are MRR and kerf. In WEDM, the material removal is by melting and/or evaporation of electrically conductive phase of MMC. Among other performance measures, the kerf that determines the dimensional accuracy of the finishing part is of extreme importance, has not been given due importance during development model in case of WEDM of MMC. Extensive experimental work is therefore needed to analyze and optimize the process parameters to understand their effect on product quality. Response surface methodology (RSM) is one emerging technique, which helps in carrying out the analysis of experiments with the least experimental effort (Montgomery, 1997). In the present work, the mathematical models were developed and also verification test for the developed models were carried out, to obtain the optimal setting of process parameters and to achieve optimum MRR and kerf on the component made of $\mathrm{SiC}_{\mathrm{p}} / 6061 \mathrm{Al} \mathrm{MMC}$ processed by WEDM process.

The present chapter contains the seven sections. Section 1 focuses on: why WEDM is important for machining of MMCs. Section 2 gives the brief introduction of WEDM and its working principle. Section 3 contains the critical review on past research work on WEDM of MMCs. Section 4 contains the details of materials and methods used during the experiments. Section 5 focuses on response surface methodology that have been used for designing the experiments. Section 6 describes the results of machinability of $\mathrm{SiC}_{\mathrm{p}} / 6061 \mathrm{Al}$ MMC during WEDM. A detailed study on the effect of process parameters on response characteristics are presented in this 
Shandilya, Pragya; Jain, P. K. \& Jain N.K.: Wire Electric Discharge Machining of...

section. Section 7 provides the conclusions from the present research work and recommendations for future work.

\section{Wire electric discharge machining (WEDM)}

Wire electric discharge machining was first introduced to the manufacturing industry in the late 1960s. The development of the WEDM process was the result of seeking a technique to machine the electrodes used in EDM. In 1974, D.H. Dulebohn applied the optical-line follower system to automatically control the shape of the component to be machined by the WEDM process (Jameson et al., 2001). By 1975, its popularity rapidly increased, as the process and its capabilities were better understood by the industry (Benedict, 1987). It was only towards the end of the 1970s, when computer numerical control (CNC) system was integrated with WEDM that brought about a major evolution of the machining process. As a result, the broad capabilities of the WEDM process were extensively exploited for any through-hole machining owing to the wire, which has to pass through the part to be machined.

\subsection{Basic principle of WEDM}

WEDM, also known as electric discharge wire cutting (EDWC), is a thermoelectric process in which material is eroded from the workpiece by a series of discrete sparks between the workpiece and a wire electrode (tool) separated by a thin film of dielectric fluid (generally deionized water) that is continuously fed to the machining zone to flush away the eroded particles. The movement of the wire is controlled numerically to achieve the desired three-dimensional shapes and accuracy of the workpiece (as shown in Fig. 1).

The wire is guided by sapphire or diamond guide and kept straight by a high value of wire tension, which is important to avoid tapering of the cut surface (Saha et al., 2005). High frequency DC pulses are delivered between the wire and workpiece, causing spark discharges in the narrow gap between the two. A stream of dielectric fluid is directed, usually coaxially with the wire, to flood the gap between the wire and workpiece. The power supply for the WEDM is essentially same as that for conventional EDM. Except that the current carrying capacity of the wire i.e. limited up to less than $20 \mathrm{~A}$. In addition, spark frequencies used are up to $1 \mathrm{MHz}$, to give a fine surface finish on the workpiece (Linkbeck et al., 1990). There is no mechanical contact between the wire and workpiece in WEDM as shown in Fig. 1, the workpiece is moved under computer numerical control (CNC) relative to the wire, and this enables complex shaped profile to be cut through sheet and plate materials. Many machines incorporate further angular positioning of the wire, thus allowing varying degrees of taper on the cut surface to be obtained. Adaptive control based on gap voltage sensing is necessary to avoid contact between the wire and the work material. Short-circuit must be sensed and the wire is backed off along the programmed path to establish the correct gap for the efficient cutting (Ramasawmy \& Blunt, 2003; Krar et al., 2005). 


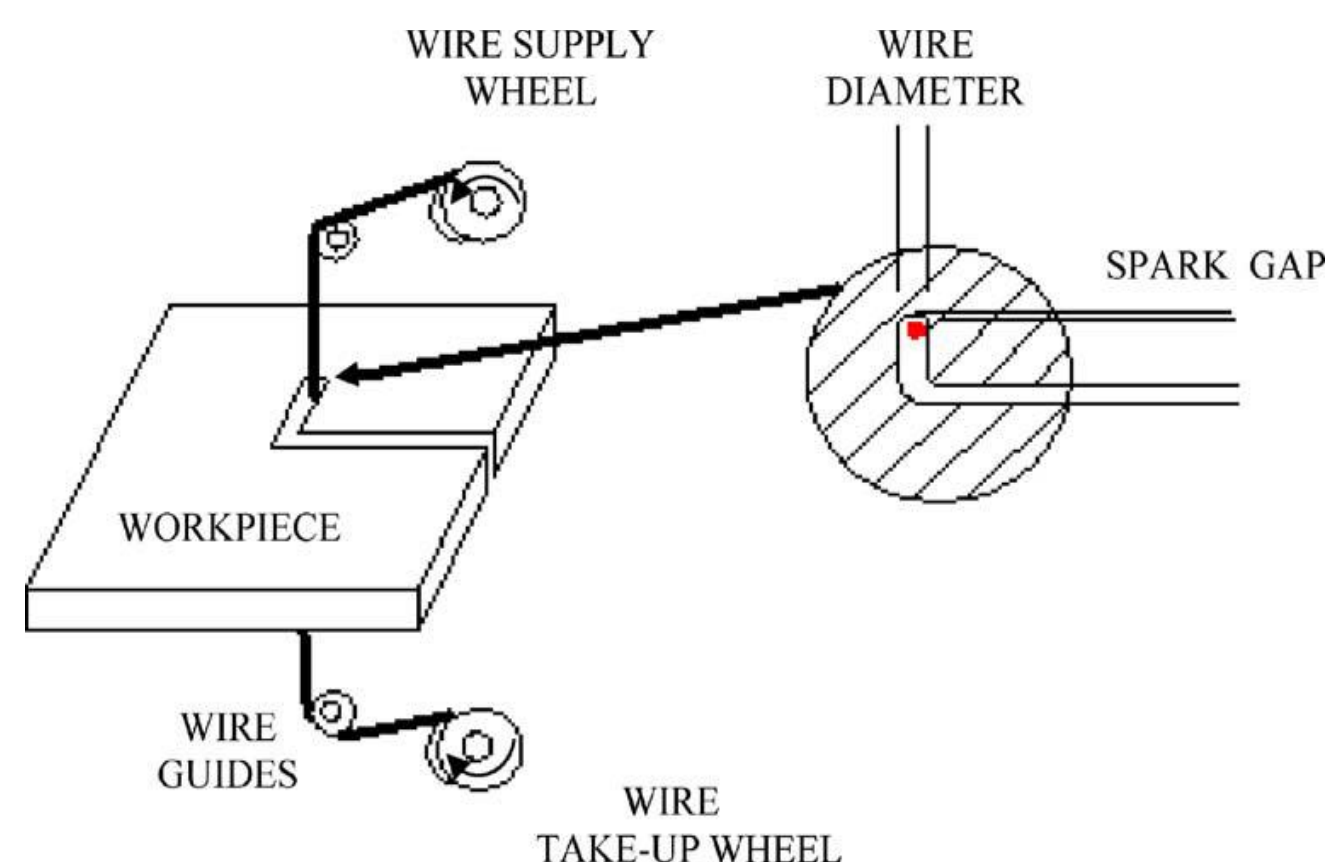

TAKE-UP WHEEL

Fig. 1. Detail of WEDM cutting gap (Benedict, 1987)

\section{Past research work on WEDM of MMCs}

Very few studies have been undertaken in WEDM of MMCs. Further, most of these studies have been done by using one-parameter-at-a-time approach, which may not explain the effects of interaction among various parameters. Some of past studies on WEDM of MMCs are presented as follow.

Gatto and Luliano (1997) performed the WEDM tests under one roughing and two finishing conditions on two composites i.e. $15 \% \mathrm{SiC}_{\mathrm{w}} / 2009 \mathrm{Al}$ and $20 \%$ $\mathrm{SiC}_{\mathrm{w}} / 2009 \mathrm{Al}$. Results show that the WEDM rates $(\mathrm{mm} / \mathrm{min})$ of both composites are equal. Rozenek et al. (2001) investigated the effect of machining parameters (discharge current, pulse-on time, pulse-off time, voltage) on the machining feed rate and surface roughness during WEDM of $\mathrm{AlSi} 7 \mathrm{Mg} / \mathrm{SiC}$ and $\mathrm{AlSi} 7 \mathrm{Mg} / \mathrm{Al}_{2} \mathrm{O}_{3} \mathrm{MMCs}$. Generally machining characteristic of metal matrix composites machined by WEDM is similar to those that occur in the base material (AlSi7Mg aluminium alloy). The machining rate of composites significantly depends on the kind of reinforcement. The maximum cutting speed of $\mathrm{AlSi} 7 \mathrm{Mg} / \mathrm{SiC}$ and $\mathrm{AlSi} 7 \mathrm{Mg} / \mathrm{Al}_{2} \mathrm{O}_{3}$ composites are approximately 3 times and 6.5 times lower than the cutting speed of aluminum alloy, respectively. Guo et al. (2002) studied the machineability of $\mathrm{Al}_{2} \mathrm{O}_{3}$ particle-reinforced $6061 \mathrm{Al}$-alloy by WEDM process. A method of orthogonal design has been used to determine the main factors that affect the machining process. The results show that the electrical discharge energy is closely related to machining stability. A good machining effect can be attained when the electrical parameters are properly selected; otherwise, the machining may be unstable resulting in wire breakage. Yan et al. (2005) used a WEDM in machining of $\mathrm{Al}_{2} \mathrm{O}_{3 \mathrm{p}} / 6061 \mathrm{Al}$ composite. The results show that the cutting speed, the surface roughness and the width of slit of cutting test material significantly depend on volume fraction of reinforcement $\left(\mathrm{Al}_{2} \mathrm{O}_{3}\right.$ particles). Test result reveals that in machining $\mathrm{Al}_{2} \mathrm{O}_{3 \mathrm{p}} / 6061 \mathrm{Al}$ composites a very low wire tension, a high flushing rate and a high wire speed are required to prevent wire breakage: an appropriate servo voltage, a short pulse-on time, and a short pulse-off 
time, which are normally associated with a high current speed, have a little effect on the surface roughness. Sarkar et al. (2006) studied the WEDM of $\gamma$ titanium aluminide. They also attempted to develop an appropriate machining strategy for a maximum process yield criteria. A feed forward back propagation neural network was used to model the machining process. The three most important parameters the cutting speed, surface roughness, and wire offset- have been considered as measures of the process performance. The model is capable of predicting the response parameters as a function of six different control parameters, i.e. pulse-on time, pulseoff time, peak current, wire tension, dielectric flow rate and servo reference voltage. Ali (2006) investigated on the effect and optimization of machining parameters on the material removal rate (MRR) and surface roughness in the WEDM process of Al$\mathrm{Cu}-\mathrm{TiC}-\mathrm{Si} \mathrm{P} / \mathrm{M}$ composite. The settings of machining parameters were determined by using Taguchi experimental design method. The variation of MRR and surface roughness with machining parameters is mathematically modeled by using non-linear regression analysis method. The optimal machining parameters for the objective of maximizing MRR and minimizing surface roughness are performed. Patil and Brahmankar (2006) investigated the effect of various control parameters such as pulse-on time, pulse-off time, ignition pulse current, wire speed, wire tension and flushing pressure on cutting speed and surface finish of $\mathrm{Al} / \mathrm{SiC}_{\mathrm{p}}$ by using Taguchi methods. Mathematical models relating the machining performance and machining parameters have been formulated. Optimal settings for each performance measure have also been obtained, a comparative study on unreinforced alloy revealed the effect of reinforcement on the machining process. It was found that the cutting speed for unreinforced alloy was higher compared to MMC. Wire breakage was found to pose limitation on the cutting speed of MMC. Saha et al. (2009) studied the machinability of $5 \%$ vol TiC/Fe in-situ metal matrix composite. Modeling of WEDM process by normalized radial base function network (NRBFN) with enhanced Kmeans clustering technique have been done which yields better results than NRBFN with traditional K-means clustering technique. Results show that an increase in the average gap voltage leads to the decrease of the cutting speed. An increase in pulseon time increases the cutting speed. Shandilya et al. (2010, a) concluded that to achieve higher value of the average cutting speed, lower value of voltage and higher value of pulse-off time should be used during WEDC of $\mathrm{SiC}_{\mathrm{p}} / 6061 \mathrm{Al} \mathrm{MMC}$. In the most recent work, Shandilya et al. (2011, a) studied the effect of input process parameters on surface surface roughness during WEDM of $\mathrm{SiC}_{\mathrm{p}} / 6061 \mathrm{Al} \mathrm{MMC}$. Results show that, voltage is the most significant parameter on surface roughness, where as pulse-on time and pulse-off time has less significant effect.

According to the literature survey it observed that very little work has been reported on WEDM of MMCs. As the $\mathrm{SiC}_{\mathrm{p}} / \mathrm{Al} \mathrm{MMCs}$ have many industrial applications but their machining by WEDM is still not well understood. There is lack of published literature, to determine the effect of input process parameters on machining of the $\mathrm{SiC}_{\mathrm{p}} / 6061 \mathrm{Al} \mathrm{MMC}$ by WEDM. Very few optimization and modeling techniques have been presented for WEDM of $\mathrm{SiC}_{\mathrm{p}} / 6061 \mathrm{Al} \mathrm{MMC}$. In the present work effect of servo voltage, pulse-on time, pulse-off time and wire feed rate on the quality of cut in terms of MRR and kerf has been evaluated during WEDM of $\mathrm{SiC}_{\mathrm{p}} / 6061$ aluminum MMC through RSM. This study gives the optimal values of 
input process parameters in which $\mathrm{WEDM}$ of $\mathrm{SiC}_{\mathrm{p}} / 6061 \mathrm{Al} \mathrm{MMC}$ is possible with maximum MRR and minimum kerf.

\section{Experimentation}

The experiments were conducted at ECOCUT WEDM Machine (supplied by Electronica India Pvt Ltd.). A schematic diagram of WEDM system is shown in Fig. 2.

In the present study $\mathrm{SiC}_{\mathrm{p}} / 6061 \mathrm{Al}$ metal matrix composite was used as the workpiece material made by stir casting technique at FENFEE Metallurgical research lab, India. Al 6061 was used as the matrix material and $\mathrm{SiC}$ particles were used as reinforcement. Al 6061 alloy has many superior mechanical properties such as low density, low melting point, high strength to weight ratio, good ductility and low cost. Al 6061 alloy is also a heat treatable, weldable and corrosion resistant material (Anon, 1990). The chemical composition of Al 6061 is shown in Table 1. The weight percentage of $\mathrm{SiC}$ was used as $10 \%$ having size of $10 \mu \mathrm{m}$ as reinforcement phase in $\mathrm{SiC}_{\mathrm{p}} / 6061 \mathrm{Al}$ MMC. WEDM process parameters that have been fixed during the experiments are listed in Table 2 . The four input parameters namely servo voltage (SV), pulse-on time $\left(\mathrm{T}_{\mathrm{ON}}\right)$, pulse-off time $\left(\mathrm{T}_{\mathrm{OFF}}\right)$ and wire feed rate $(\mathrm{WF})$ were chosen as variables to study their effects on the quality of cut in $\mathrm{SiC}_{\mathrm{p}} / 6061$ aluminum MMC using MRR and kerf as response parameters. Table 3 gives the levels of various parameters that have been selected on the basis of preliminary experimental investigation and machining constants (Shandilya et al., 2011, b). The following equation is used to determine the MRR value (Nito et al., 2006):

$$
M R R=\frac{M_{f}-M_{i}}{\rho t}
$$

Where $M_{i}, M_{f}$ are masses (in gm) of the work material before and after machining respectively, $\rho$ is the density of work piece material and $t$ is the time of machining in minutes. An electronic weighing machine with an accuracy of $0.1 \mathrm{mg}$ was used to measure the initial and final weight of the workpice.

kerf is expressed as sum of wire diameter and twice of wire-work piece gap as given in following equation.

$$
k e r f=(d+2 W g)
$$

Where $d$ is the wire diameter and $W g$ is the wire workpiece gap in which spark is produced during the machining.

\begin{tabular}{|l|l|l|l|l|l|l|l|l|}
\hline Element & $\mathrm{Al}$ & $\mathrm{Si}$ & $\mathrm{Mg}$ & $\mathrm{Cu}$ & $\mathrm{Mn}$ & $\mathrm{Cr}$ & $\mathrm{Fe}$ & $\mathrm{Ti}$ \\
\hline $\begin{array}{l}\text { Composition } \\
\text { (wt\%) }\end{array}$ & 95.83 & 0.68 & 1.20 & 0.61 & 0.45 & 0.50 & 0.27 & 0.46 \\
\hline
\end{tabular}

Tab. 1. Chemical composition of Al $6061 \mathrm{MMC}$ 
MACHINE TOOL

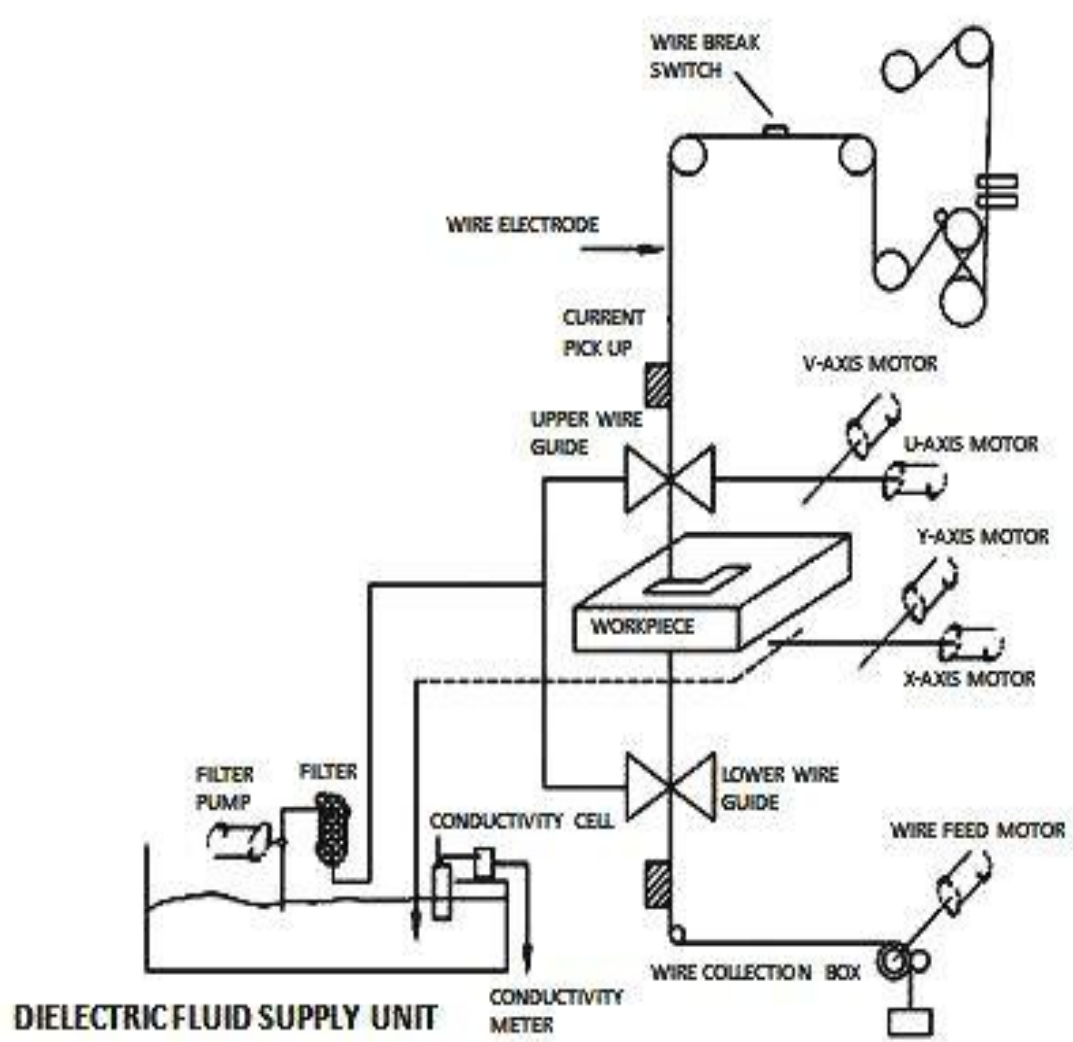

CNCPULSE GENERATOR

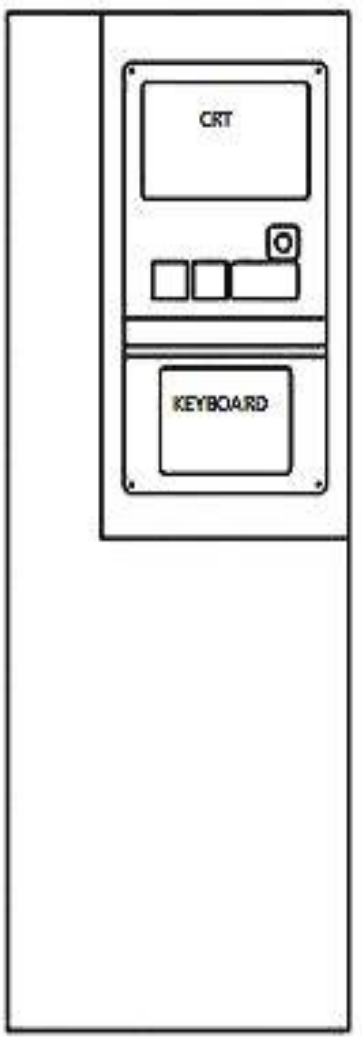

Fig. 2. Schematic representation of the WEDM system (Electronica, India)

\begin{tabular}{|c|c|c|}
\hline S.No & Parameter & Level \\
\hline 1 & Wire material & Diffused brass wire \\
\hline 2 & Wire size $(\mathrm{mm})$ & $\varnothing 0.25$ \\
\hline 3 & Wire tension $(\mathrm{gm})$ & 1600 \\
\hline 4 & Dielectric & Deionised water \\
\hline 5 & Table feed rate $(\mathrm{mm} / \mathrm{min})$ & $\mathrm{Al} / \mathrm{SiC}_{\mathrm{p}}$ \\
\hline 6 & Workpiece & 10 \\
\hline 7 & Workpiece thickness $(\mathrm{mm})$ & 20 \\
\hline 8 & Room Temperature $\left({ }^{\circ} \mathrm{C}\right)$ & \\
\hline
\end{tabular}

Tab. 2. Machining parameters set up (constant parameters)

\begin{tabular}{|c|c|c|c|}
\hline \multirow{2}{*}{ Process parameters } & \multicolumn{3}{|c|}{ Levels } \\
\cline { 2 - 4 } & -1 & 0 & +1 \\
\hline Voltage $(\mathrm{V})$ & 70 & 80 & 90 \\
\hline Pulse-on time $(\mu \mathrm{s})$ & 1 & 2 & 3 \\
\hline Pulse-off time $(\mu \mathrm{s})$ & 6 & 8 & 10 \\
\hline Wire feed $(\mathrm{m} / \mathrm{min})$ & 5 & 7 & 9 \\
\hline
\end{tabular}

Tab. 3. Levels of process parameters 


\section{Response surface methodology}

Response surface methodology approach is the procedure for determining the relationship between various process parameters with various machining criteria and exploring the effects of these process parameters on the coupled responses (Myers and Montgomery, 2002). In order to study the effect of WEDM process parameters of $\mathrm{SiC}_{\mathrm{p}} / 6061 \mathrm{Al} \mathrm{MMC}$ on MRR and kerf, a second order polynomial response can be fitted into the following equation:

$$
\begin{aligned}
& Y=b_{0}+b_{1} x_{1}+b_{2} x_{2}+b_{3} x_{3}+b_{4} x_{4}+b_{11} x_{1}^{2}+b_{22} x_{2}^{2}+b_{33} x_{3}^{2}+b_{44} x_{4}^{2}+b_{12} x_{1} x_{2}+ \\
& b_{13} x_{1} x_{3}+b_{14} x_{1} x_{4}+b_{23} x_{2} x_{3}+b_{24} x_{2} x_{4}+b_{34} x_{3} x_{4}
\end{aligned}
$$

Where $\mathrm{Y}$ is the response and $x_{1}, x_{2}, x_{3}, x_{4}$ are the quantitative variables. $b_{1}, b_{2}$, $b_{3}$ and $b_{4}$ represent the linear effects of $x_{1}, x_{2}, x_{3}$ and $x_{4}$ respectively, $b_{11}, b_{22}, b_{33}$ and $b_{44}$ represent the quadratic effects of $x_{1}, x_{2}, x_{3}$ and $x_{4} . b_{12}, b_{13}, b_{14}, b_{23}, b_{24}$ and $b_{34}$ represent linear-by-linear interaction between $x_{1}$ and $x_{2}, x_{1}$ and $x_{3}, x_{1}$ and $x_{4}, x_{2}$ and $x_{3}, x_{2}$ and $x_{4}, x_{3}$ and $x_{4}$, respectively. These quadratic models work quite well over the entire factor space and regression coefficients were computed according to the leastsquares procedure (Shabgard and Shotorbani, 2009).

By plotting the expected response of $\mathrm{Y}$, a surface, known as the response surface is obtained. The WEDM process was studied according to the box behnken design (BBD). Levels and values for four factors have been given in Table 3. In this investigation, total 29 experiments were conducted. The 'Design Expert 6.0' software was used for regression and graphical analysis of the data obtained. The optimum values of the selected variables were obtained by solving the regression equations and by analyzing, the response surface contour plots. Analysis of variance was used to analyze the experimental data and the relative importance of the machining parameters with respect to the measure of performance was investigated.

\section{Experimental results and discussions}

Table 4 illustrates the order, combination and design of experiments based on the coded surfaces and results of the desired response surface.

\subsection{Analysis of Variance (ANOVA)}

ANOVA was used to analyze the experimental data using model summary statistics and lack of fit tests and to determine the relative importance of the machining parameters with respect to the measure of performance. It also shows the value of $R^{2}$-statistic and adjusted $R^{2}$-statistic. The $R^{2}$-statistic is defined as the ratio of variability explained by the model to the total variability in the actual data and is used as a measure of the goodness of fit. The more $\mathrm{R}^{2}$ approaches unity, the better model fits the experimental data. The adjusted $\mathrm{R}^{2}$-statistic is a statistic which is adjusted for the 'size' of the model; i.e. number of factors (terms). ANOVA tables for $\mathrm{SiC}_{\mathrm{p}} / 6061$ 
Al MMC of MRR and kerf are presented in Table 5 and Table 6 respectively. According to the analysis done by the Design Expert software, if the values of probability (Prob $>\mathrm{F}$ ) are less than 0.05 , it indicated that the factors is significant to the response parameters.

\begin{tabular}{|c|c|c|c|c|c|c|}
\hline Exp. & $\begin{array}{c}\text { Voltage, } \\
\text { A } \\
\text { No. } \\
(\mathrm{V})\end{array}$ & $\begin{array}{c}\text { Pulse- } \\
\text { on } \\
\text { time, } \\
\text { B } \\
(\mu \mathrm{s})\end{array}$ & $\begin{array}{c}\text { Pulse- } \\
\text { off } \\
\text { time, } \\
\text { C } \\
(\mu \mathrm{s})\end{array}$ & $\begin{array}{c}\text { Wire } \\
\text { Feed } \\
\text { rate, D } \\
(\mathrm{m} / \mathrm{min})\end{array}$ & $\begin{array}{c}\text { MRR } \\
\left(\mathrm{mm}^{3} / \mathrm{min}\right)\end{array}$ & $\begin{array}{c}\text { Kerf } \\
(\mathrm{mm})\end{array}$ \\
\hline 1 & 0 & 1 & 0 & -1 & 4.200 & 0.381 \\
2 & -1 & 0 & 0 & -1 & 9.965 & 0.266 \\
3 & 0 & 0 & 1 & 1 & 4.931 & 0.328 \\
4 & -1 & 0 & 1 & 0 & 5.188 & 0.287 \\
5 & 0 & -1 & -1 & 0 & 4.586 & 0.359 \\
6 & 1 & 0 & 0 & -1 & 3.679 & 0.415 \\
7 & 1 & 0 & -1 & 0 & 3.026 & 0.438 \\
8 & 0 & 0 & 0 & 0 & 3.243 & 0.424 \\
9 & 0 & 0 & 0 & 0 & 3.943 & 0.387 \\
10 & 1 & 0 & 0 & 1 & 5.072 & 0.308 \\
11 & 0 & 0 & 1 & -1 & 3.897 & 0.407 \\
12 & 0 & 0 & 0 & 0 & 3.939 & 0.394 \\
13 & 0 & -1 & 0 & 1 & 4.740 & 0.342 \\
14 & 0 & 0 & 0 & 0 & 3.170 & 0.426 \\
15 & 0 & 1 & 0 & 1 & 5.075 & 0.302 \\
16 & 0 & 0 & 0 & 0 & 3.293 & 0.422 \\
17 & 1 & 0 & 1 & -1 & 4.702 & 0.352 \\
18 & 0 & 1 & -1 & -1 & 4.974 & 0.322 \\
19 & 0 & 0 & -1 & 1 & 4.340 & 0.368 \\
20 & 0 & -1 & 0 & -1 & 4.251 & 0.372 \\
21 & 0 & 0 & -1 & -1 & 4.851 & 0.334 \\
22 & 0 & -1 & 1 & 0 & 3.901 & 0.401 \\
23 & 1 & 1 & 0 & 0 & 2.590 & 0.446 \\
24 & -1 & 0 & -1 & 0 & 11.354 & 0.261 \\
25 & -1 & 1 & 0 & 0 & 5.991 & 0.274 \\
26 & -1 & 0 & 0 & 1 & 5.126 & 0.294 \\
27 & -1 & -1 & 0 & 0 & 5.325 & 0.282 \\
28 & 1 & -1 & 0 & 0 & 3.132 & 0.432 \\
29 & 0 & 1 & 1 & 0 & 4.997 & 0.316 \\
& & & & & & \\
\hline
\end{tabular}

Tab. 4. BBD with four parameters and experimental, MRR and kerf

Table 5 shows that voltage $(\mathrm{V})$, pulse-off time $\left(\mathrm{T}_{\mathrm{OFF}}\right)$, wire feed rate $(\mathrm{WF})$, quadratic effect of voltage $(\mathrm{V} \times \mathrm{V})$, quadratic effect of pulse-off time $\left(\mathrm{T}_{\mathrm{OFF}} \times \mathrm{T}_{\mathrm{OFF}}\right)$, quadratic effect of wire feed rate $(\mathrm{WF} \times \mathrm{WF})$, interaction effect of voltage with pulse- 
off time $\left(\mathrm{V} \times \mathrm{T}_{\mathrm{OFF}}\right)$ and interaction effect of voltage with wire feed rate $(\mathrm{V} \times \mathrm{WF})$ have significant effects on MRR. The lack of fit was not significant which satisfy the model to be fitted. The obtained value of 0.8695 for $\mathrm{R}^{2}$ implies that the model explains approximately $86.95 \%$ of the variability in MRR. The value of adjusted $\mathrm{R}^{2}$ statistic is equal to 0.8173 for MRR indicates that $81.73 \%$ of the total variability is explained by the model after considering the significant factors.

For kerf result of ANOVA analysis as given in Table 6 shows that voltage (V), pulse-off time $\left(\mathrm{T}_{\mathrm{OFF}}\right)$, wire feed rate $(\mathrm{WF})$, quadratic effect of voltage $(\mathrm{V} \times \mathrm{V})$, quadratic effect of pulse-off time $\left(\mathrm{T}_{\mathrm{OFF}} \times \mathrm{T}_{\mathrm{OFF}}\right)$, quadratic effect of wire feed rate $(\mathrm{WF} \times \mathrm{WF})$, interaction effect of voltage with wire feed rate $(\mathrm{V} \times \mathrm{WF})$ and interaction effect of pulse-off time with wire feed rate $\left(\mathrm{T}_{\mathrm{OFF}} \times \mathrm{WF}\right)$ have significant effects. The lack of fit was not significant which satisfy the model to be fitted. The obtained value of 0.8827 for $\mathrm{R}^{2}$ implies that the model explains approximately $88.27 \%$ of the variability in kerf. The value of adjusted $\mathrm{R}^{2}$-statistic is equal to 0.7655 for kerf indicates that $76.55 \%$ of the total variability is explained by the model after considering the significant factors.

\begin{tabular}{|l|l|l|l|l|}
\hline Parameters & Sum of Squares & DF & F Value & P value \\
\hline Voltage $(V)$ & 26.86 & 1 & 32.63 & $<0.0001$ \\
Pulse-on time $\left(T_{O N}\right)$ & 0.15 & 1 & 0.18 & 0.6809 \\
Pulse-off time $\left(T_{O F F}\right)$ & 19.99 & 1 & 24.28 & 0.0002 \\
Wire feed rate $(W F)$ & 12.08 & 1 & 14.67 & 0.0018 \\
Quad. $V(V \times V)$ & 11.49 & 1 & 13.96 & 0.0022 \\
Quad. $T_{O N}\left(T_{O N} \times T_{O N}\right)$ & 0.065 & 1 & 0.079 & 0.7823 \\
Quad. $T_{O F F}\left(T_{O F F} \times T_{O F F}\right)$ & 5.73 & 1 & 6.96 & 0.0195 \\
Quad. $W F(W F \times W F)$ & 4.90 & 1 & 5.95 & 0.0286 \\
Interaction $\left(V \times T_{O N}\right)$ & 0.36 & 1 & 0.44 & 0.5164 \\
Interaction $\left(V \times T_{O F F}\right)$ & 15.37 & 1 & 18.67 & 0.0007 \\
Interaction $(V \times W F)$ & 9.71 & 1 & 11.79 & 0.0040 \\
Interaction $\left(T_{O N} \times T_{O F F}\right)$ & 0.13 & 1 & 0.15 & 0.7023 \\
Interaction $\left(T_{O N} \times W F\right)$ & 0.037 & 1 & 0.045 & 0.8346 \\
Interaction $\left(T_{O F F} \times W F\right)$ & $3.915 E-003$ & 1 & $4.755 E-003$ & 0.9460 \\
\hline
\end{tabular}

Standard deviation $=0.79$

Mean $=10.34$

Predicted residual error of sum of squares $=12.42$

R-Squared $=0.8695$

Adjusted R-Squared $=0.8173$ 


\subsection{Optimization of response parameters}

Optimization of responses were performed to determine the optimal values of input process parameters for the desired MRR and kerf based on the developed mathematical models (i.e. equations 4 and 5). The 'Design Expert 6.0' software was used to optimize the responses during WEDM of $\mathrm{SiC}_{\mathrm{p}} / 6061 \mathrm{Al} \mathrm{MMC}$. The target values for the MRR were set as maximum and for kerf as minimum. The optimal values of input process parameters as obtained are listed in Table 7. The process inputs need some modification for machine constraints. The value of composite desirability D, was taken as 1 (Montgomery, 1997).

An experiment was carried out at the optimal parametric settings for MRR and kerf so that targeted value of response parameter can be obtained. Table 8 shows the predicted value of MRR and kerf obatined from the mathematical relationships as given in equations 4 and 5 respectively and experimental results with the parameteric optimal setting as obtained from RSM model. The predicted values of responses were compared with the respective experimental values and the absolute percentage error was computed as follows:

$$
\% \text { Absolute error }=\left|\frac{Y j, \text { expt-Yj,pred }}{Y j, \text { expt }}\right| * 100
$$

Where Yj,expt is the experimental value and Yj,pred is the predictive value of the response for the $j$ th trail by the RSM model. Prediction are in good agreement with the experimental results for MRR as compared to kerf because the percentage error of the predicted value with respect to the experimentally observed value for MRR is $4.26 \%$ whereas for kerf is $10.52 \%$.

\begin{tabular}{|c|c|c|c|c|c|c|c|}
\hline \multicolumn{3}{|c|}{ Optimize value of input parameters } & \multicolumn{4}{c|}{ Modified value of inputs parameters } \\
\hline $\begin{array}{c}S V \\
(\mathrm{~V})\end{array}$ & $\begin{array}{c}T_{\text {ON }} \\
(\mu \mathrm{s})\end{array}$ & $\begin{array}{c}T_{\text {OFF }} \\
(\mu \mathrm{s})\end{array}$ & $\begin{array}{c}W F \\
(\mathrm{~m} / \mathrm{min})\end{array}$ & $\begin{array}{c}S V \\
(\mathrm{~V})\end{array}$ & $\begin{array}{c}T_{\text {ON }} \\
(\mu \mathrm{s})\end{array}$ & $\begin{array}{c}T_{O F F} \\
(\mu \mathrm{s})\end{array}$ & $\begin{array}{c}W F \\
(\mathrm{~m} / \mathrm{min})\end{array}$ \\
\hline 71.01 & 1.00 & 6.04 & 5.17 & 70.00 & 1.00 & 6.00 & 5.00 \\
\hline
\end{tabular}

Tab. 7. Optimized input process parameters

\begin{tabular}{|c|c|c|c|}
\hline Response & Predicted value $(\mu \mathrm{m})$ & Experimental value $(\mu \mathrm{m})$ & $\%$ error \\
\hline & & & \\
\hline RR & 11.354 & 11.86 & $4.26 \%$ \\
\hline
\end{tabular}

Tab. 8. Optimum values of response parameters

\subsection{Effect of input process parameters on MRR}

Fig. 3 depicts the effect of voltage, pulse-on time, pulse-off time and wire feed rate on MRR during WEDM of $\mathrm{SiC}_{\mathrm{p}} / 6061 \mathrm{Al} \mathrm{MMC}$. According to the trend, the value of MRR decreases with increase in voltage because at higher voltage, the dielectric strength of the medium increases and discharge current during machining decreases, resulting to lower melting and evaporation of the workpiece material, as a result the MRR decreases. Increase in pulse-on time, resulting the lower MRR. This 
Shandilya, Pragya; Jain, P. K. \& Jain N.K.: Wire Electric Discharge Machining of...

figure also shows that pulse-off time and wire feed rate have less significant effect on MRR.

\subsection{Effect of input process parameters on kerf}

Fig. 4 shows the effect of voltage, pulse-on time, pulse-off time and wire feed rate on kerf during WEDM of $\mathrm{SiC}_{\mathrm{p}} / 6061 \mathrm{Al} \mathrm{MMC}$. It can be seen that the value of kerf increases with increase in voltage because as the voltage increases the gap between the wire and workpiece also increases. At the same time when gap between the workpiece and wire electrode increases, the electrode wire tries to maintain the same gap surrounding the wire. This gap corresponds to the set value of voltage, and as a consequence the kerf also increases. The value of kerf increases with increase in pulse-on time.

The pulse-off time has less significant effect on kerf. The kerf increases continuously with increase in wire feed rate upto midium level of wire feed rate and than start decreasing with increase in wire feed rate.

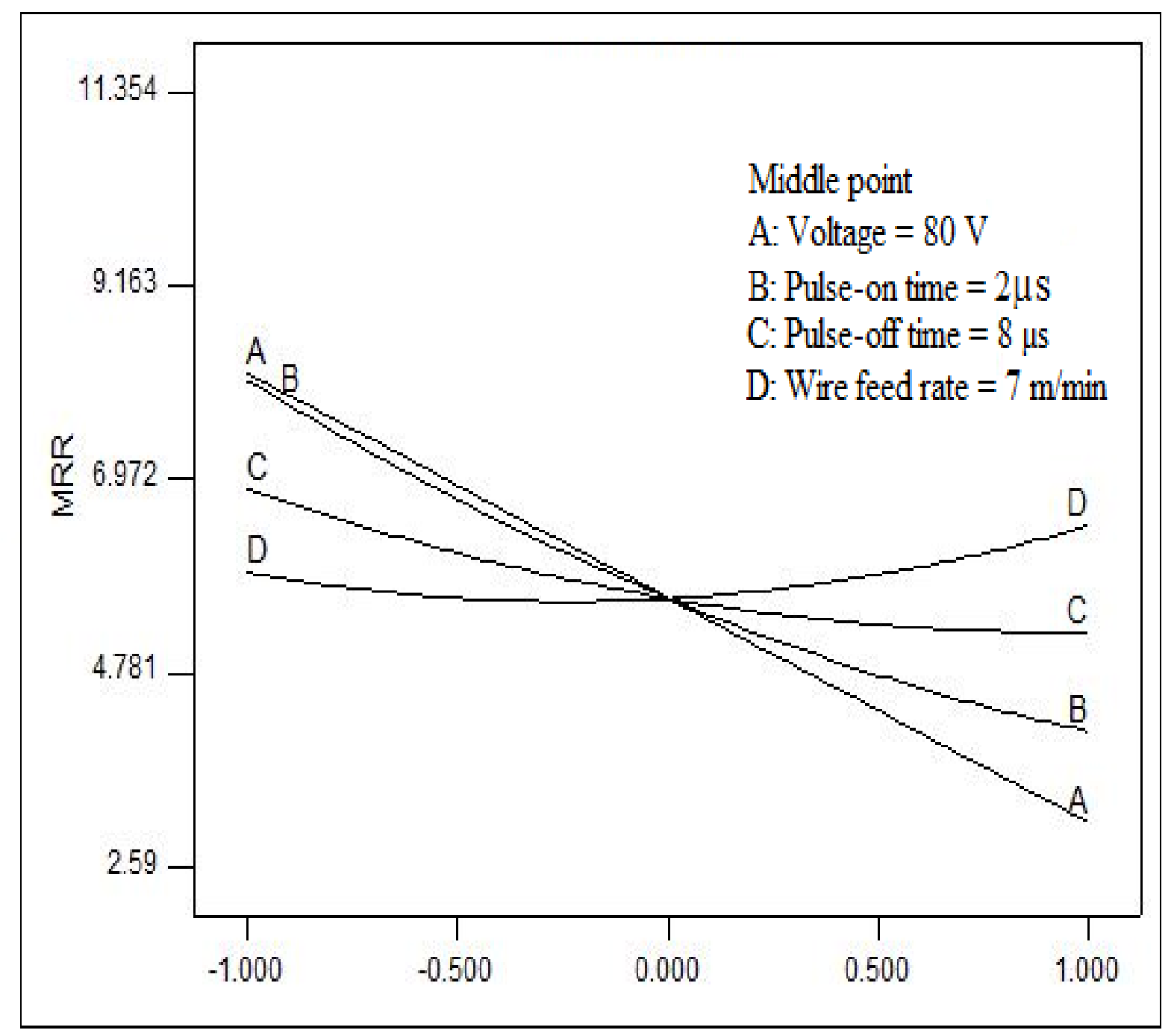

Fig. 3. Effect of voltage, pulse-on time, pulse-off time and wire feed rate on MRR [X-axis in coded value] 


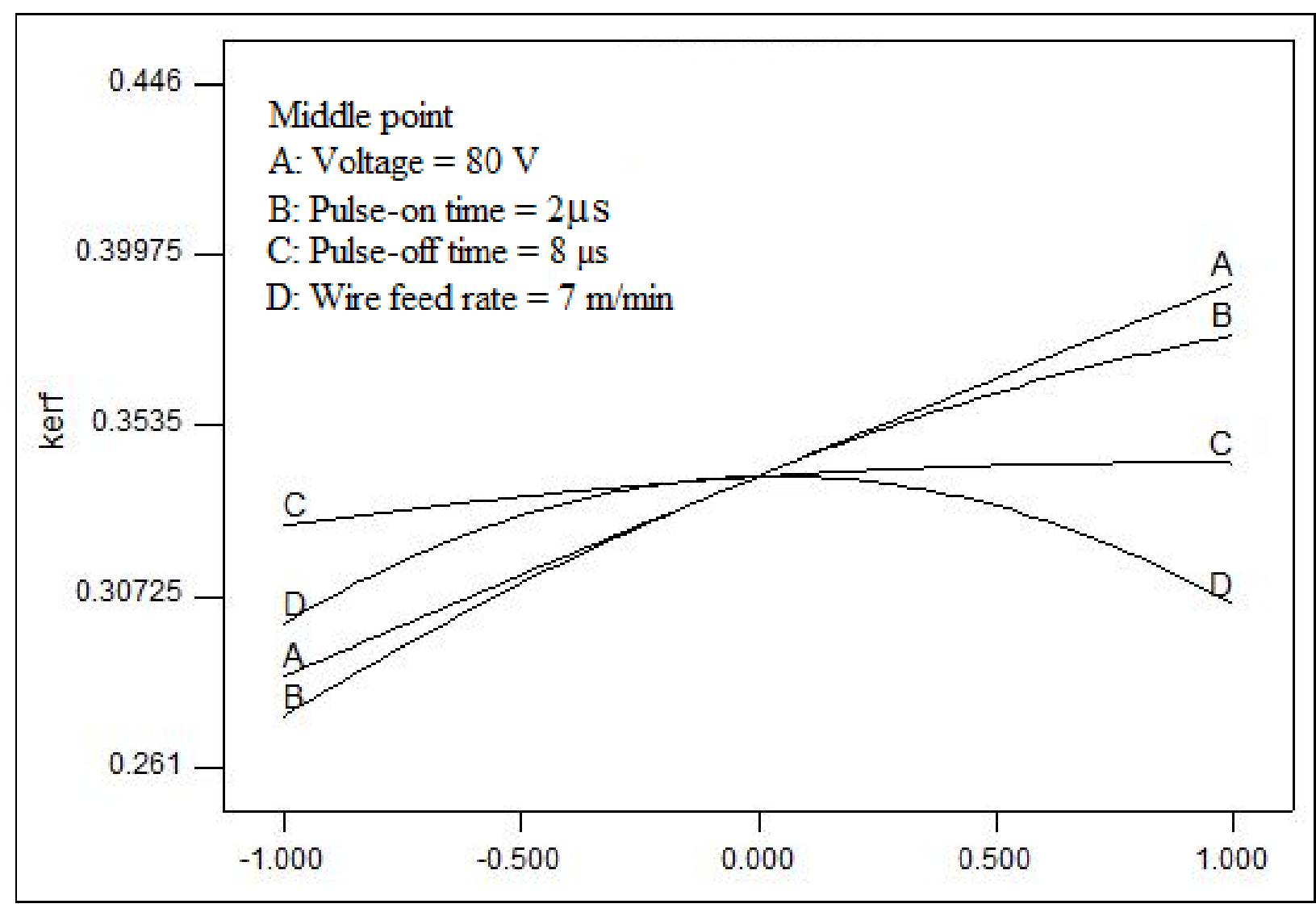

Fig. 4. Effect of voltage, pulse-on time, pulse-off time and wire feed rate on kerf [Xaxis in coded value]

\section{Conclusions}

The main objective of the WEDM process is to achieve an accurate and efficient machining operation without affecting the performance of machine. In this work, an attempt was made to consider the effect of voltage, pulse-on time, pulse-off time and wire feed rate on MRR and kerf in WEDM of $\mathrm{SiC}_{\mathrm{p}} / 6061 \mathrm{Al}$ MMC. According to the ANOVA results, voltage is the most significant parameter on MRR and kerf where as pulse-off time and wire feed rate are less significant. Pulse-on time has insignificant effect on MRR and kerf. Based on the optimization results, it has been found that $71.01 \mathrm{~V}$ as voltage, $1.00 \mu \mathrm{s}$ as pulse-on time, $6.04 \mu \mathrm{s}$ as pulse off time and $5.17 \mathrm{~m} / \mathrm{min}$ wire feed rate are optimum for the present study. The predicted value of MRR and kerf found close to the experimental value at optimum level of input process parameters. Predictions are in good agreement with the experimental results for MRR as compared to kerf because the percentage error of the predicted value with respect to the experimentally observed value for kerf is higher.

Effect of input process parameters show that maximum value of MRR and minimum value of kerf are obtained at lower level of voltage, lower level of pulse-on time.

The results of the present study based on RSM approach can be used for effective and economical machining of $\mathrm{SiC}_{\mathrm{p}} / 6061 \mathrm{Al} \mathrm{MMC}$ by WEDM. The present 
work is focused on the WEDM of $\mathrm{SiC}_{\mathrm{p}} / 6061 \mathrm{Al}$ MMCs having $\mathrm{SiC}$ particles upto $10 \%$. In future the study can be extended by using different percentage of $\mathrm{SiC}$ particles in MMC and different work material. Levels of various process parameters like wire tension, table feed rate etc. that have been fixed during this study may be varied for further investigations to determine the machinability of MMCs during WEDM. Similarly, effect of process parameters on other performance measures such as surface integrity aspects and surface texture of machined surface may be investigated.

\section{References}

Ali, T. (2006). Parametric study and optimization of wire electrical discharge machining of Al-Cu-TiC-Si P/M Composite, International Journal of Machining and Machinability of Materials, Vol. 1,(4), 380-395, 17485711

Anon (1990). Properties of wrought aluminum and aluminum alloys $\left(10^{\text {th }}\right.$ edition), ASM Metals Handbook, Vol. 2, 62-122, ASM International, Metals Park, Ohio

Benedict, G.F. (1987). Electrical discharge wire cutting (EWDC), Non Traditional Manufacturing Processes, 234-235, Marcel Dekker, Inc, 0824773527, New York \& Basel

Gatto, A.; Luliano, L. (1997). Cutting mechanism and surface features of WED machined metal matrix composites, Journal of Materials Processing Technology, Vol., 65, 209-214, 09240136

Guo, Z.N.; Wang, X.; Huang, Z.G. \& Yue, T.M. (2002). Experimental investigation into shaping particle-reinforced material by WEDM-HS, Journal of Materials Processing Technology, Vol., 129, 56-59, 09240136

Hashim,J.; Looney, L. \& Hashimi M.S.J. (1999). Metal matrix composites: production by the stir casting method, Journal of Materials Processing Technology, Vol.,92, 1-7, 09240136

Hung, N.P.; Yang, L.J. \& Leong, K.W. (1994). Electro discharge machining of cast metal matrix composites. Journal of Materials Processing Technology, Vol.,44, 229-236, 09240136

Jameson, E.C. (2001). Description and development of electrical discharge machining (EDM), Electrical Discharge Society of Manufacturing Engineers, Dearborn, Machigan, 16

Krar, S.F.; Gill, A.R. \& Smid, P. (2005). Electrical discharge machining, Technology of Machine Tools, 831-836

Lau, W.S. \& Lee W.B. (1991). Comparison between EDM wire cut and laser cutting of carbon fiber composite materials, Materials and Manufacturing Processes, Vol.,6 (2), 331-342

Lindroos, V.K. \& Talvitie, M.J. (1995). Recent advances in metal matrix composites. Journal of Materials Processing Technology, Vol.,53, 273-284, 09240136

Linkbeck, J.R.; Williams, M.W. \& Wygant, R.M. (1990). Manufacturing technology special machining methods, Electrical Discharge Machining, pp.316-318 
Monaghan, J.M. \& Reilly, P.O. (1992). The drilling of an Al/SiC Metal matrix composite, Journal of Materials Processing Technology, Vol.,33 (4), 469-480, 09240136

Montgomery, D.C. (2001). Design and analysis of experiments, John Wiley and sons, New York

Muller, F. \& Monaghan J. (2000). Non- conventional machining particle metal matrix composite, International Journal of Machine tools and Manufacture, Vol.,40 (9), 1351-1366, 08906955

Myers, R.H. \& Montgomery, D.C. (2002). Response surface methodology: process and product optimization using designed experiments, Second edition (2002) Wiley, New York

Nito, J.C.S.; Silva, E.M. \& Silva, M.B. (2006). Intervening variables in electrochemical machining. Journal of Materials Processing Technology; Vol.,179 (1-3), 92-96, 09240136

Patil, N.G. \& Brahmankar, P.K. (2006). Some investigations into wire electrodischarge machining performance of $\mathrm{Al} / \mathrm{SiC}_{\mathrm{p}}$ composites, International Journal of Machining and Machinability of Materials, Vol., 1 (4), 412-431, 17485711

Patil, N.G. \& Brahmankar, P.K. (2010). Some studies into wire electro-discharge machining of alumina particulate reinforced aluminum matrix composites, International Journal of Advanced Manufacturing Technology, Vol.,48, 537555,14333015

Ramasawmy, H. \& Blunt, L. (2003). Effect of EDM process parameters on 3D Surface Topography, Journal of Materials Processing Technology, Vol.,148, $155-164,09240136$

Rosso, M. (2006). Ceramic and metal matrix composites: routes and properties. Journal of Materials Processing Technology, Vol.,175, 364-375, 09240136

Rozenek, M.; Kozak, J.; Dabrowski, L. \& Lubkowski, K. (2001). Electrical discharge machining characteristics of metal matrix composites, Journal of Materials Processing Technology, Vol. 109, 367-370, 09240136

Saha, P.; Tarafdar, D.; Pal, S. K.; Srivastava, A.K. \& Das K. (2009). Modeling of wire electro-discharge machining of $\mathrm{TiC} / \mathrm{Fe}$ in situ metal matrix composite using normalized RBFN with enchanced K-means clustering technique, International Journal of Advanced Manufacturing Technology, Vol.,43, 107116, 14333015

Saha, S.; Pachon, M. \& Ghoshal, A. (2005). Finite element modeling and optimization to prevent breakage in electro-discharge machining, 451-463

Sarkar, S.; Mitra, S. \& Bhattacharyya, B. (2006). Parametric optimization of wire electrical discharge machining of $\gamma$ titanium aluminide alloy through an artificial neural network model, International Journal of Advanced Manufacturing Technology, Vol., 27, 501-508, 14333015 
Shandilya, Pragya; Jain, P. K. \& Jain N.K.: Wire Electric Discharge Machining of...

Shabgard, M.R. \& Shotorbani, R.M (2009). Mathematical modeling of machining parameters in electrical discharge machining of FW4 welded steel. World Academy of Science, Engineering and Technology, Vol.,53, 403-409

Shandilya Pragya, Jain P.K. (2010), Experimental investigation during WEDC of $\mathrm{SiC}_{\mathrm{P}} / 6061 \mathrm{Al}$ MMC, Annals for DAAAM \& proceedings of the $21^{\mathrm{st}}$ International DAAAM Symposium, Vol.21, (1), pp 1091-1092, 17269679

Shandilya, P.; Jain, P.K. \& Jain, N.K. (2011, a). Modeling and analysis of surface roughness in WEDC of $\mathrm{SiC}_{\mathrm{p}} / 6061 \mathrm{Al}$ MMC through response surface methodology, International Journal of Engineering Science and Techanology, Vol.,3 (1), 531-535, 09755462

Shandilya, P.; Jain, P.K. \& Jain, N.K. (2011, b). Experimental studies on wire electric discharge cutting of $\mathrm{SiC}_{\mathrm{p}} / 6061$ aluminum metal matrix composites, Key Engineering Materials, Vol. 450, 173-176, 10139826

Yan, B.H. \& Wang, C.C. (1993). Machinability of SiC particle reinforced aluminum alloy composite material, Journal of Japan Institute Light Metals, Vol.,43 (4), 187-192, 04515994

Yan, B.H.; Tsai, H.C.; Huang, F.Y. \& Lee, L.C. (2005). Examination of wire electrical discharge machining of $\mathrm{Al}_{2} \mathrm{O}_{3} / 6061 \mathrm{Al}$ composites, International Journal of Machine Tools \& Manufacture, Vol., 45, 251-259, 08906955 